\title{
Low microwave brightness temperatures in central Antarctica: observed features and implications
}

\author{
Sylviane SURDYK \\ Institute of Low Temperature Science, Hokkaido University, Sapporo 060-0819, Japan
}

\begin{abstract}
The microwave brightness temperature of the ice sheet in Antarctica has a few narrow, elongated features of very low microwave brightness temperatures. The contrast inside and outside of these areas is at least $10 \mathrm{~K}$ at $37 \mathrm{GHz}$. These features are persistent throughout the year and from year to year and occur at 6.6, 10.7, 18 and $37 \mathrm{GHz}$. The exceptionally large frequency gradients observed in this narrow area suggest that very large snow grains exist in the snow cover. Past traverse data revealed that the entire surrounding region undergoes large temperature gradients that drive high sublimation causing very large snow grains to form and the formation of both surface and depth hoar. A detailed study of former snow pits showed that, at the place of the unique features, the snow grains from the surface down to the first $2 \mathrm{~m}$ are the largest observed over the region. A digital elevation model shows the surface is nearly flat, and corresponds to a subglacial depression in the underlying bed. Previously reported kilometer-scale snow dunes are observed up- and downslope of the level area, but not within the level area, where the brightness temperature is lowest. In this katabatic zone, the drift-snow redistribution and the natural wind-shadow induced by the slope depression create a protected area where the snow grains can grow into very large grains.
\end{abstract}

\section{INTRODUGTION}

Previous studies have shown that the microwave brightness temperature is linked to the snow temperature, snow layering, snow density and crystal sizes and shapes (Hall, 1987; Mätzler, 1987; Fily and Benoist, 1991; Rott and others, 1993; Surdyk and Fily, 1995). These results provided some understanding of the snow characteristics in Antarctica on a large scale. However, studies of local snow properties remain limited, partly due to the lack of ground observations. Thus, gaining a better understanding of microwave-snow interactions is an ongoing process. The recent digital elevation model (DEM) from European Remote-sensing Satellite-1 (ERS-1) (Liu and others, 1999) and the bedrock topography model from the BEDMAP consortium (Lythe and others, 2001) allow additional data to be used for understanding local features. A correlation between bedrock topography, surface topography and accumulation environment has been established in a few regions in Antarctica (Budd, 1970; Goodwin, 1988; Takahashi and others, 1994). Surface undulations created originally by the ice flow over the bedrock topography create an inhomogeneous depositional environment. This process includes inhomogeneous vertical strain rate and wind erosion, modifying the snow-cover characteristics (Parish and Bromwich, 1987). This paper describes one such case. Hereafter, TB denotes the vertically polarized brightness temperature, with subscripts for frequency (e.g. $\mathrm{TB}_{37}$ is the vertically polarized brightness temperature at $37 \mathrm{GHz}$ ).

The map in Figure 1 shows surface elevation and the mean annual $\mathrm{TB}_{37}$. The brightness temperature decreases gradually inland from the coast. The coldest surface air temperatures are at the highest elevation, but these regions are not regions of lowest brightness temperatures (dark area, Fig. 1), because the brightness temperature is also dependent on snow properties. Past investigations indicate that the presence of very coarse snow grains, mainly depth hoar, is a plausible explanation for these low brightness temperatures (Surdyk and Fily, 1993). Surface and depth hoar are known to significantly decrease the emissivity (Hall, 1987; Surdyk and Fily, 1995; Abdalati and Steffen, 1998). The dark area in Figure 1 corresponds also to the largest seasonal amplitude of the brightness temperature, 20$25 \mathrm{~K}$, which suggests that this area undergoes large seasonal changes. Giovinetto (1963) concluded that the large seasonal temperature gradient observed in the region associated with low accumulation rates leads to the development of the observed very coarse snow grains, mainly depth hoar.

In that dark area, there are three black elongated features with $\mathrm{TB}_{37}$ below $175 \mathrm{~K}$, the lowest brightness temperature observed over Antarctica at $37 \mathrm{GHz}$. Hereafter, the features are denoted $\underline{\mathrm{a}}, \underline{\mathrm{b}}$ and $\underline{\mathrm{c}}$ patches. The largest patch, patch $\underline{\mathrm{c}}$, is about $600 \mathrm{~km}$ long and $120 \mathrm{~km}$ wide. These patches are persistent at $\mathrm{TB}_{37}$ on vertical and horizontal polarization of Scanning Multichannel Microwave Radiometer (SMMR) and Special Sensor Microwave/Imager (SSM/I) data throughout the year and from 1978 until now. A sharp contrast of brightness temperature inside and outside of this area of about $10 \mathrm{~K}$ within $25 \mathrm{~km}$ indicates that it can be explained only by a relatively large change in snow-cover properties. Fahnestock and others (2000) also mentioned this low-brightness-temperature area when discussing the presence of a snow-megadune field in central Antarctica. They describe "megadunes" as 2-4 km wavelength ripples, observed through Advanced Very High Resolution Radiometer imagery and synthetic aperture radar (SAR) data. Megadunes have an amplitude of a few meters and can extend $100 \mathrm{~km}$ (Fahnestock 
and others, 2000). In their analysis, Fahnestock and others (2000) placed the dune fields at the location of the low brightness temperature. We note the snow megadunes are found only in this central part of Antarctica where TB is low, but not where it is lowest. The present study reveals that the dune fields are located up- and downslope of the low-TB patches. Apparently unchanged since 1963, these dune fields reflect persistent katabatic wind activity (Fahnestock and others, 2000). The dunes are too small to be detected with passive microwave, but their presence is important.

How snow properties relate to the brightness-temperature pattern here is examined using a DEM, the RADARSAT SAR mosaic, some ground observation and previous results on microwave-snow interactions. The bedrock and surface slope are related: the slope of the surface that controls the regional wind activity influences the growth of snow grains into large grains, depth hoar, and the depth hoar reduces the brightness temperature.

\section{DESGRIPTION OF THE DATA}

\subsection{Passive-microwave dataset}

The passive-microwave data used for this study are from the SMMR on board the Nimbus 7 satellite that operated from October 1978 to August 1987. The SMMR sensor measured both vertical and horizontal polarizations at 6.6, 10.7, 18, 21 and $37 \mathrm{GHz}$. The incident angle was about $50^{\circ}$ from zenith. No data are available south of $84^{\circ} \mathrm{S}$. The spatial resolution varied from $150 \mathrm{~km}$ at $6.6 \mathrm{GHz}$ to $30 \mathrm{~km}$ at $37 \mathrm{GHz}$, but the data were interpolated to a $25 \mathrm{~km}$ grid spacing, which is the same grid as the more recent $\mathrm{SSM} / \mathrm{I}$. The latter is a common grid in polar stereographic projection, with $70^{\circ} \mathrm{S}$ as the latitude of true scale and $0^{\circ} \mathrm{E}$ as the central meridian. The exact position of each gridpoint in latitude and longitude was obtained with the program "locate" provided with the $\mathrm{SSM} /$ I dataset.

The mean annual brightness-temperature data from 1984 were used. These data are plotted in one and two dimensions at the various frequencies and polarizations. The two-dimensional gray-scale plots use the gridded dataset. The onedimensional curves were computed for every $5 \mathrm{~km}$ along the defined route, and used linearly interpolated data based on gridpoints within $37.5 \mathrm{~km}$ of each plotted point.

\subsection{Surface and bedrock elevation datasets}

To estimate the surface and bedrock elevations, the DEM and the bedrock topography model (BEDMAP), respectively, were used (Liu and others, 1999; Lythe and others, 2001). They are presented on a $5 \mathrm{~km}$ grid in polar stereographic projection, with $71^{\circ} \mathrm{S}$ as the latitude of true scale and $0^{\circ} \mathrm{E}$ as the central meridian. To precisely locate each gridpoint the "locate" program was used after adjusting the true latitude to $71^{\circ} \mathrm{S}$, the grid size and the center of the grid.

Surface elevations along the A-B-C route (Fig. 1) used linearly interpolated DEM data based on gridpoints within $7.5 \mathrm{~km}$ of each plotted point, computed every $1 \mathrm{~km}$ along the defined route. Surface slope was computed on a $5 \mathrm{~km}$ grid from the first derivative of the DEM dataset. Surface slope along the A-B-C route was calculated with the same interpolation as for surface elevations.

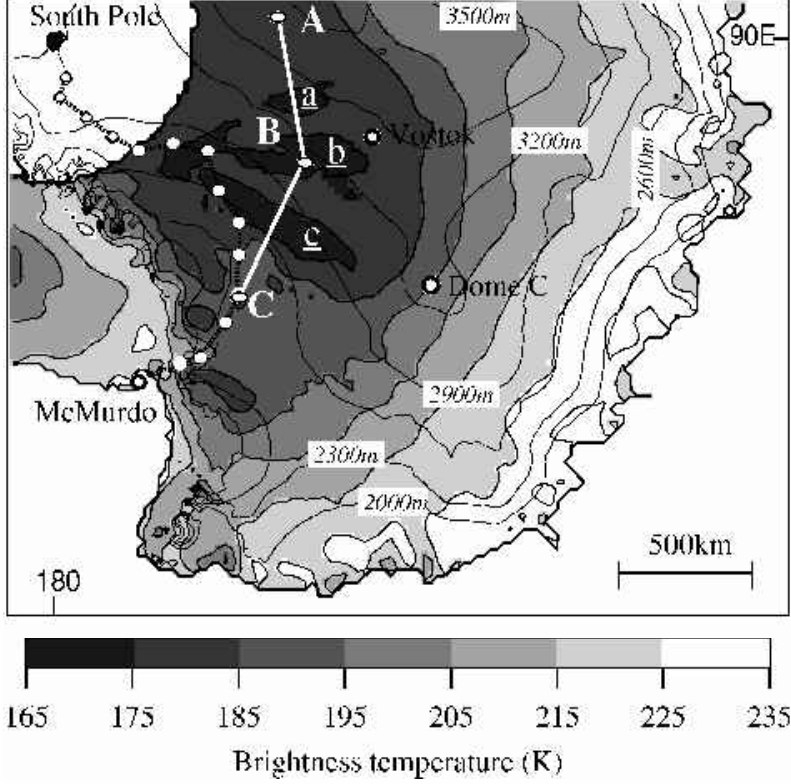

Fig. 1. Map of the 1984 mean annual $37 \mathrm{GHz}$ brightness temperature in Antarctica with elevation contour lines. The upper-left white area, south of $84^{\circ} S$, is a region where no data are available. The black patches bound by $175 \mathrm{~K}$ contours are marked $\underline{a}, \underline{b}$ and $\underline{c}$. The data along line $A-B-C$ are studied in detail. White circles are stations where the snow properties were analyzed during the McMurdo-South Pole traverse in 1960/61. Position $A$ is $82.24^{\circ} \mathrm{S}, 84.03^{\circ} \mathrm{E} ; \mathrm{B}$ is $80.37^{\circ} \mathrm{S}$, $116.26^{\circ} \mathrm{E}$; and $\mathrm{C}$ is $78.96^{\circ} \mathrm{S}, 145.15^{\circ} \mathrm{E}$.

\subsection{SAR data}

The Canadian RADARSAT SAR 125 m resolution was used to map the location of the snow-megadune fields (Fahnestock and others, 2000). The data used are not the original SAR data but the gray-scale image dataset.

The snow megadunes reported by Fahnestock and others (2000) were located visually on the RADARSAT SAR mosaic by a typical pattern of light and dark ripples, extending from wavelengths of a few kilometers to a few tens of kilometers to several hundred kilometers. Because the RADARSAT mosaic uses the same projection as the DEM, the "locate" program was used to transfer the megadunes to the map of brightness temperatures. Grid size and center of the grid have been adjusted.

\subsection{Ground-observation dataset}

Direct measurements of snow grain-sizes, snow layering and crust layers came from a traverse during winter 1960/61. This started from McMurdo $\left(77.8^{\circ} \mathrm{S}, 166.6^{\circ} \mathrm{E}\right)$ and followed the route to the South Pole shown in Figure 1 (Giovinetto, 1963). Although these data are much older than the satellite data, it is assumed here that the general surface characteristics did not change dramatically between 1961 and 1984. This 23 year time gap is a concern due to known climate change in Antarctica (Houghton and others, 1990); however, the TB gray-scale plots have changed insignificantly between 1978 and 2001, the period for which satellite data are available. 


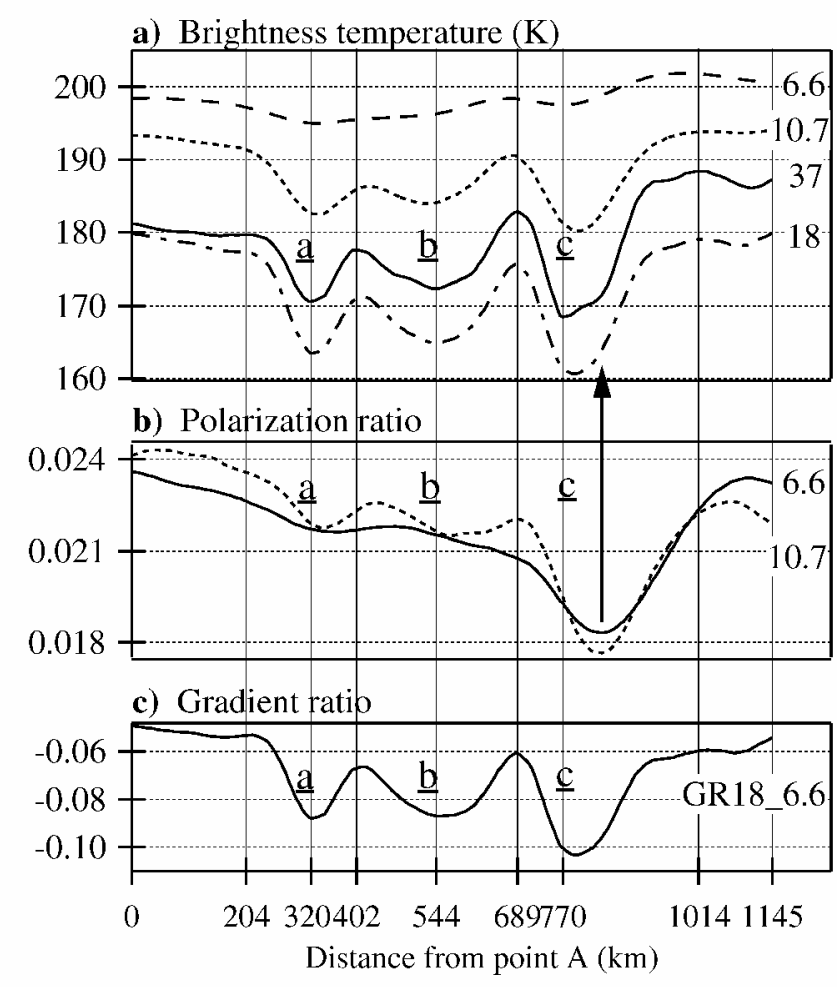

Fig. 2. Satellite-derived data along line A-B-C. (a) Brightness temperatures from the four SMMR frequencies; $(b)$ polarization ratios (ratio of the difference between vertical and horizontal signals to their sum); (c) gradient ratio (the ratio of the $18 \mathrm{GHz}$ to the $6.6 \mathrm{GHz}$ signal). The horizontal axis is the distance from point $A$ shown in Figure 1. The distance on the abscissa is based on the gridcell dimensions. The local extrema of $T B_{37}$ are marked by vertical gray lines, and their distances are labeled on the abscissa.

\section{DESGRIPTION OF THE BRIGHTNESS TEMPERATURE}

\subsection{General features of the low brightness temperatures}

The low-TB patches are most distinct at $37 \mathrm{GHz}$, but are also discernible at lower frequency. In patch $\mathrm{c}$, the seasonal amplitude of $\mathrm{TB}_{18}$ is $>15 \mathrm{~K}$, which is larger than in any other region. This patch also has some of the largest seasonal amplitudes at $10.7 \mathrm{GHz}$, at little more than $6.5 \mathrm{~K}$. At $6.6 \mathrm{GHz}$, only a weak seasonal pattern appears in horizontal polarization near patch $\underline{\mathrm{c}}$. This decreasing seasonal amplitude with frequency can be partly explained by the corresponding drop in the sensor's resolution: from $50 \mathrm{~km}$ at $18 \mathrm{GHz}$ to $100 \mathrm{~km}$ at $10.7 \mathrm{GHz}$, and $150 \mathrm{~km}$ at $6.6 \mathrm{GHz}$, the latter of which exceeds the width of the largest patch, patch $\mathrm{c}$. When we degrade the resolution of all the channels to $150 \mathrm{~km}$ by applying a running mean, the difference inside and outside of the patches decreased by $50 \%$ for patch $\underline{\mathrm{c}}, 65 \%$ for patch $\underline{\mathrm{b}}$ and $80 \%$ for patch a. The low TBs observed on the patches occur at nearly all frequencies both throughout the year and from year to year. Therefore, the specificity of the patches is not temporal nor is it limited to the near surface.

\subsection{Detailed features of the low brightness temperatures}

To analyze the patches in detail, I focus on the brightness tem- peratures at the four SMMR frequencies along the A-B-C route (Fig. 1 map). This route was chosen to cover the three patches.

\section{Brightness temperatures}

Figure $2 \mathrm{a}$ shows $\mathrm{TB}_{6.6}, \mathrm{~TB}_{10.7}, \mathrm{~TB}_{18}$ and $\mathrm{TB}_{37}$ along line A-B-C. All the TBs drop significantly at the three patches, although this is not so clear at $6.6 \mathrm{GHz}$. The drop is greatest at patch $\underline{\mathrm{c}}$ where it is also the sharpest because the patch is only $120 \mathrm{~km}$ across. This drop is $14 \mathrm{~K}$ for $\mathrm{TB}_{37}$ and $\mathrm{TB}_{18}, 9 \mathrm{~K}$ for $\mathrm{TB}_{10.7}$, and $1 \mathrm{~K}$ for $\mathrm{TB}_{6.6}$. Such a significant change over a short distance reflects a drastic change in snow characteristics, not only in the near surface (i.e. $\mathrm{TB}_{37}, \mathrm{~TB}_{18}$ ), but also at depth $\left(\mathrm{TB}_{10.7}\right.$, $\mathrm{TB}_{6.6}$ ). The penetration depths for frequencies below $10 \mathrm{GHz}$ vary from several meters to a few tens of meters.

$\mathrm{TB}_{37}$ and $\mathrm{TB}_{18}$ have distinct maxima at 402 and $689 \mathrm{~km}$ (Fig. 2a). Assuming that the emissivity equals the observed mean annual TB divided by the mean annual air temperature, the emissivity is approximately 0.82 at the four maxima (204, 402,689 and $1014 \mathrm{~km}$ ), whereas it is $0.75-0.78$ at the minima. The temperatures were estimated from a $-50^{\circ} \mathrm{C}$ isotherm at $3000 \mathrm{~m}$ and a previously measured lapse rate of $1.1^{\circ} \mathrm{C}$ per $100 \mathrm{~m}$ (Giovinetto, 1963). The same emissivity at each maximum might indicate that the snow cover generally has uniform conditions except at the three patches.

\section{Polarization ratios}

The polarization ratio is defined as follows:

$$
\mathrm{PR}=\frac{\mathrm{TB}_{\mathrm{v}}-\mathrm{TB}_{\mathrm{h}}}{\mathrm{TB}_{\mathrm{v}}+\mathrm{TB}_{\mathrm{h}}},
$$

where $\mathrm{TB}_{\mathrm{v}}$ and $\mathrm{TB}_{\mathrm{h}}$ are the vertical and horizontal components of the brightness temperature. Figure $2 \mathrm{~b}$ displays the profiles of $\mathrm{PR}_{6.6}$ and $\mathrm{PR}_{10.7}$. The $\mathrm{PR}_{10.7}$ shows two clear maxima, like $\mathrm{TB}_{37}$. The minima are also distinct, although the minimum of patch $\underline{\mathrm{c}}$ is shifted by about $70 \mathrm{~km}$. A vertical gray arrow in Figure $2 \mathrm{~b}$ indicates that the location of $\mathrm{PR}_{10.7}$ 's minimum does not correspond to $\mathrm{TB}_{37}$ 's minimum value but is still within the patch's minimum values, i.e. $<175 \mathrm{~K}$. The $\mathrm{PR}_{6.6}$ shows no clear maxima, but a distinct minimum appears on patch c as on $\mathrm{PR}_{10.7}$. Surdyk and Fily $(1993,1995)$ found that the PRs at frequencies lower than $10 \mathrm{GHz}$ were a good indicator of the stratification into the snow cover: the higher the PR, the larger is the number of strata over the first $2 \mathrm{~m}$. Each stratum is defined when the density or the grainsize of the snow or icy layer changes. Following Surdyk and Fily, the locations of the $\mathrm{PR}_{10.7}$ maxima correspond to places with relatively high stratification (large number of strata over the first few meters) compared to the locations of minima. Therefore, the stratification is lower in the patches area, i.e. either the snow layers are thicker or the number of crust layers is smaller, or both.

\section{Gradient ratio}

The gradient ratio discussed here is the frequency gradient between $18 \mathrm{GHz}$ and $6.6 \mathrm{GHz}$ in vertical polarization, $\mathrm{GR}_{18-6.6}$. It is defined as follows:

$$
\mathrm{GR}_{18 \_6.6}=\frac{\overline{\mathrm{TB}_{18}}-\overline{\mathrm{TB}_{6.6}}}{\overline{\mathrm{TB}_{18}}+\overline{\mathrm{TB}_{6.6}}},
$$

where $\overline{\mathrm{TB}_{18}}$ and $\overline{\mathrm{TB}_{6.6}}$ are the annual means. Figure $2 \mathrm{c}$ displays the profile of $\mathrm{GR}_{18 \_6.6}$. The ratio $\mathrm{GR}_{18 \_6.6}$ is strongly correlated with $\mathrm{TB}_{37}$. Surdyk and Fily (1993) made an intercomparison of observed $2 \mathrm{~m}$ snow stratigraphies, collected over Antarctica during the International Geo- 
a) Surlace inclination ( $\mathrm{m} \mathrm{km}^{-1}$ )

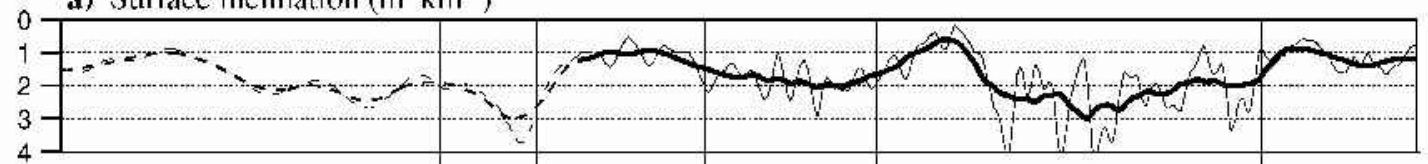

b) Brightness temperature (K) (leff scale) and surface elevation (m) (right scale)

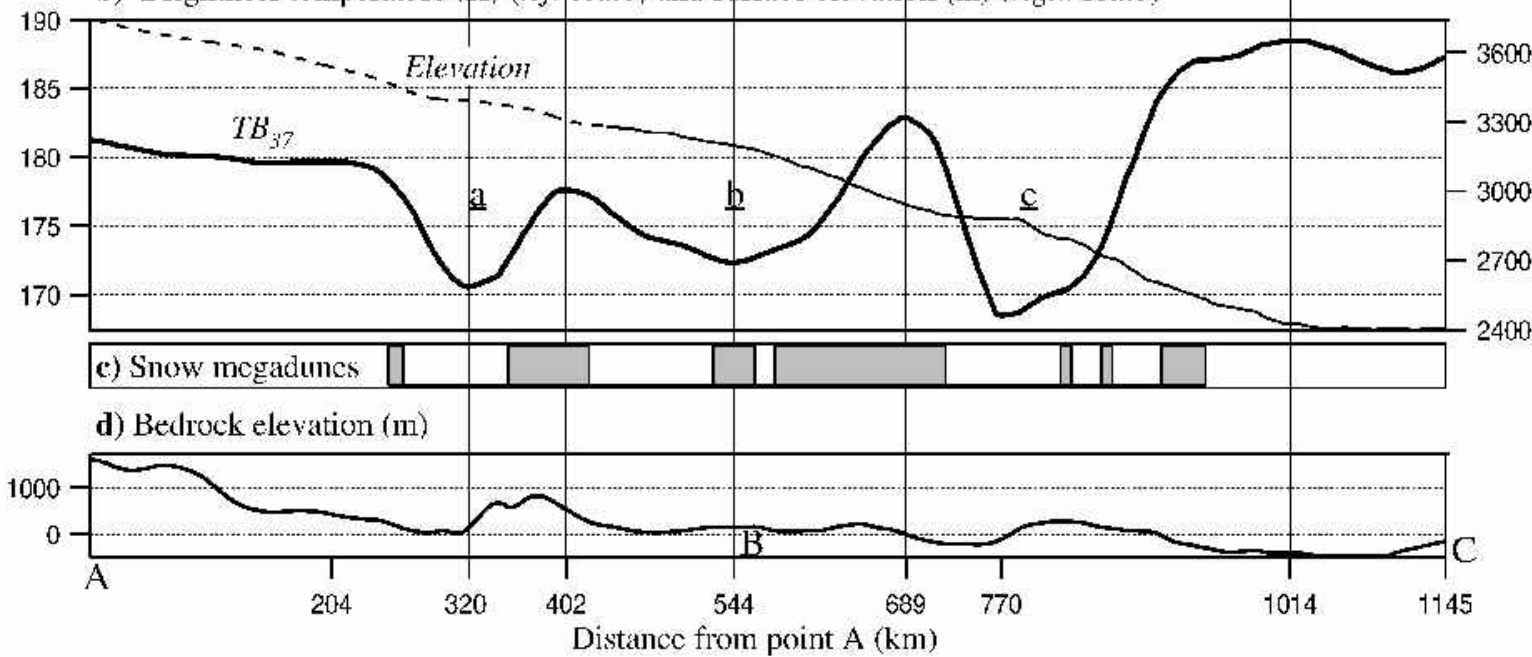

Fig. 3. Comparison of brightness temperature to surface topography, bedrock topography and the snow megadunes' location along line A-B-C. (a) The surface inclination derived from the surface elevation dataset; the thick line is a $50 \mathrm{~km}$ running average. (b) The brightness temperature TB 37 and the surface elevation. (c) The snow megadunes' location extracted from the Antarctic RADARSAT SAR mosaic. (d) The bedrock topography. Between 0 and $440 \mathrm{~km}$, the surface slope and surface elevation curves are represented as dashed lines (see section 4 for explanation).

physical Year 1957/58, and the brightness-temperature signature at SMMR frequencies. They found a correlation between $\mathrm{GR}_{18-6.6}$ and the mean snow grain-size over the first $2 \mathrm{~m}$ : the larger the grains, the lower the ratio (Surdyk and Fily, 1993). Therefore, the gradient ratio (Fig. 2c) indicates that higher $\mathrm{TB}_{37}$ corresponds to smaller snow grains than low $\mathrm{TB}_{37}$, i.e. the snow grains are larger in the patches than outside.

To summarize, the satellite data indicate that high $\mathrm{TB}_{37}$ corresponds to areas where the snow cover is highly stratified with relatively small snow grains, and low $\mathrm{TB}_{37}$ corresponds to areas with low stratification and large snow grains.

\section{COMBINATION WITH THE DEM}

In Figure 3, $\mathrm{TB}_{37}$ is displayed along with the corresponding surface DEM and the surface inclination. The DEM was built from ERS-1 radar altimetry and is accurate to $2 \mathrm{~m}$ over the ice sheet (Liu and others, 1999). However, south of $81.5^{\circ} \mathrm{S}$, beyond the reach of the satellite's sensor, the data are interpolated with other existing datasets and are less accurate (Liu and others, 1999). For this reason, the surface elevation and inclination curves in Figure 3 are indicated by a dashed line from 0 to $440 \mathrm{~km}$. Beyond $440 \mathrm{~km}$, the surface inclination has short-scale fluctuations, particularly between 800 and $1000 \mathrm{~km}$. By analyzing ERS-1 altimetry data in the area $120-140^{\circ} \mathrm{E}, 74-81^{\circ} \mathrm{S}$, Brisset and Rémy (1996) found a $20 \mathrm{~km}$ wavelength undulation with $10 \mathrm{~m}$ amplitude, and attributed it to ice flowing over irregular bedrock. The surface inclination curve was smoothed at a $50 \mathrm{~km}$ scale to determine the regional trend of the surface inclination. For patch a, the accuracy of the surface inclination is poor (south of $81.5^{\circ} \mathrm{S}$ ), but the two remaining patches show a very specific pattern. Assuming an initial stage at a local maximum, $\mathrm{TB}_{37}$ starts to dropjust after the slope starts significantly decreasing. The minimum in $\mathrm{TB}_{37}$ occurs in the latter part of the level area. Then in the sloping part, $\mathrm{TB}_{37}$ increases slowly for several tens of $\mathrm{km}$, and finally, as the slope remain steep, increases sharply to reach a new maximum. The bedrock elevation is also drawn in Figure 3; level surfaces are located just above depressions in the bedrock (Budd, 1970).

Figure 4 shows the low-TB patches with their $175 \mathrm{~K}$ contour lines superimposed on a map of the surface inclination. This two-dimensional image shows, as in Figure 3, that patch

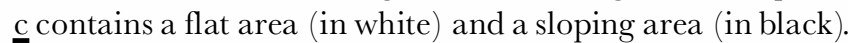
Patch $\underline{c}$ fits throughout its length to the slope-break area; this probably explains the particular elongated shape of the patch. For patch $\underline{b}$, the light-dark color contrast over the patch is

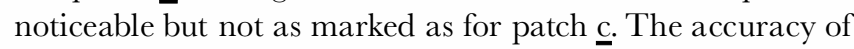
the surface slope over patch a is not sufficient for conclusions to be drawn.

In summary, the strong changes of $\mathrm{TB}_{37}$ strongly correlate to changes of slope. The low $\mathrm{TB}_{37}$ values occur in areas where the surface is nearly level, and extend into regions where the elevation starts decreasing.

\section{RADARSAT SAR DATA AND THE SNOW- MEGADUNE FIELDS}

Figure 3 displays the locations of the snow-dune fields along the A-B-C route. The snow megadunes are essentially located upand downslope of half of the patches. Considering that the patches overlap a level area, this observation would be expected since the snow megadunes reflect the regular katabatic wind activity, itself controlled by the regional surface slope (Fahnestock and others, 2000). Figure 5 shows the location of the snow megadunes relative to the low- $\mathrm{TB}_{37}$ 


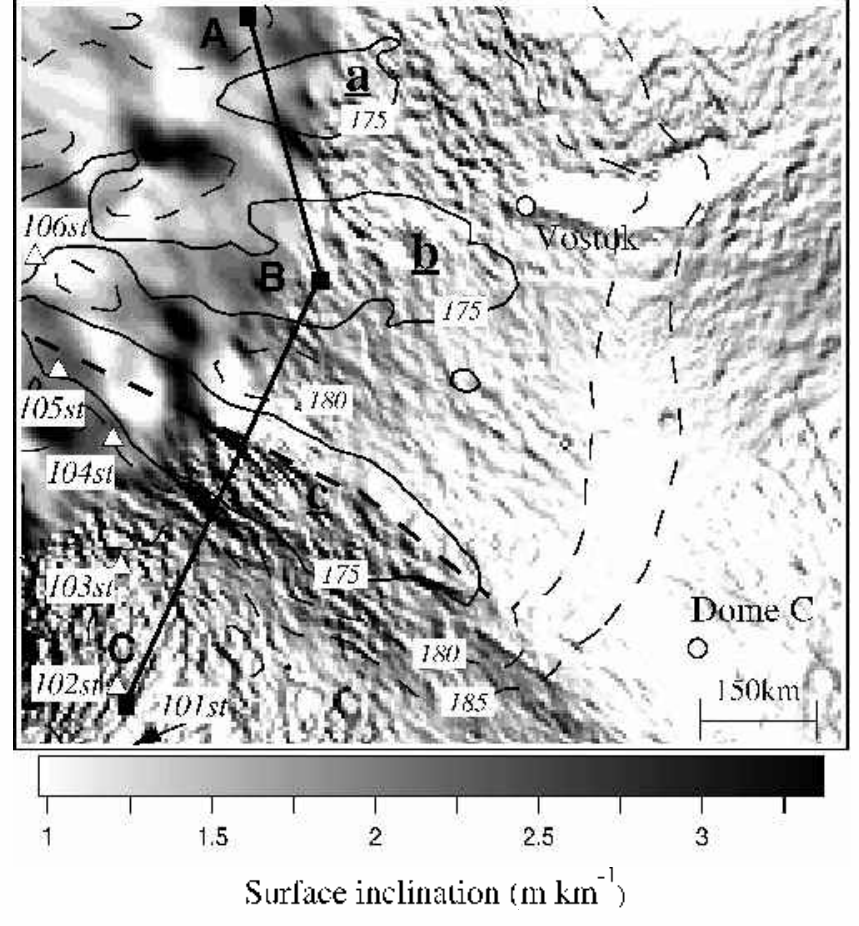

Fig. 4. Surface inclinations near the low-brightness-temperature patches that are bound by $175 \mathrm{~K}$ contour lines. The whitest areas are nearly flat, with a surface inclination $<1 \mathrm{~m} \mathrm{~km}^{-1}$. The thick

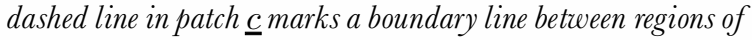
significantly different slope. Line $A-B-C$ is marked as a thick line. Inland stations (circles) and snow-pit locations along the McMurdo-South Pole traverse (triangles) are also labeled.

patches over the studied area. This two-dimensional representation shows that the snow-megadune locations do not correspond to the patches but are shifted downslope. Patches $\underline{a}$ and $\underline{\mathrm{c}}$ are relatively clear of snow megadunes, which cover $<20 \%$ of the area, but the coverage of patch $\underline{b}$ is about $50 \%$.

The above observation confirms the conclusion of

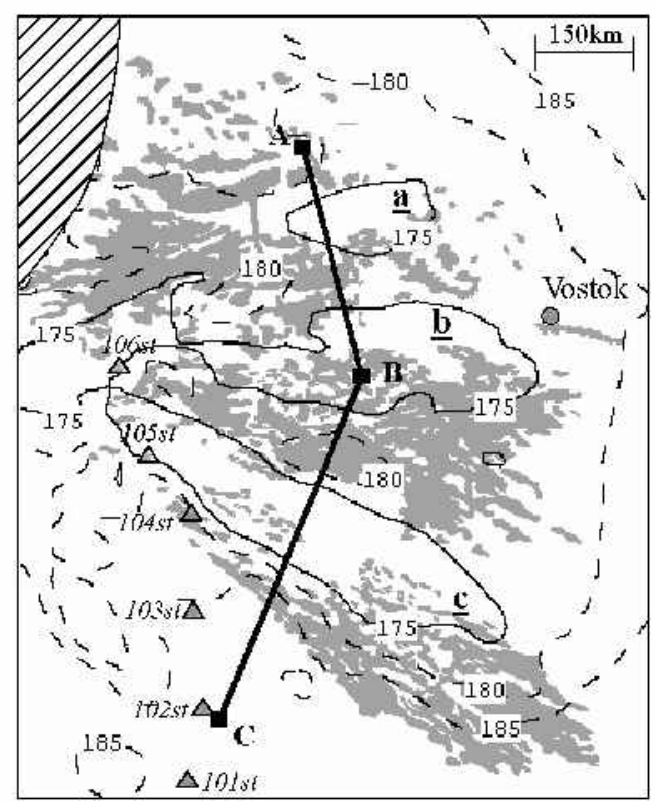

Fig. 5. Location of the snow-megadune fields (gray color) in the area of the patches. Annotations are the same as for Figure 4; the dashed area in the upper left corner indicates an area with no SMMR data available ( south of $84^{\circ} \mathrm{S}$ ).
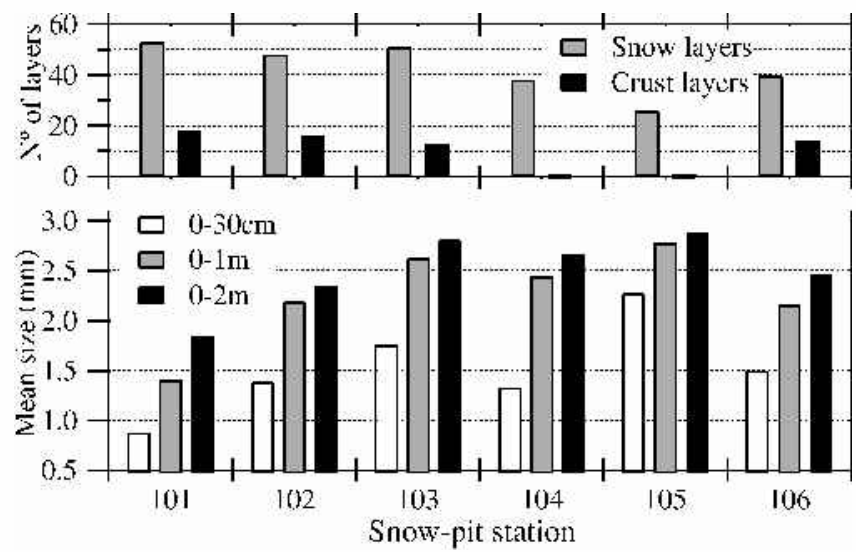

Fig. 6. Measured crystal sizes and layering in snow pits along the McMurdo-South Pole traverse (Giovinetto, 1963) that are labeled in Figure 5. The bottom graph gives the mean snow-crystal size over the top $30 \mathrm{~cm}$, the top $1 \mathrm{~m}$ and the top $2 \mathrm{~m}$. The top graph gives the number of snow layers and number of crust layers in the top $2 \mathrm{~m}$. These layers were determined by the traverse expedition, but did not precisely define what constitutes a layer. However, only the trend is important for this work.

section 4, that the patches appear in an area where the wind action is weakened or non-existent, i.e. a level area and a few tens of kilometers downslope.

\section{SNOW-PIT MEASUREMENTS}

Along the traverse that links McMurdo to the South Pole, Giovinetto (1963) reported a uniform depth-firn temperature of $-45^{\circ}$ to $-50^{\circ} \mathrm{C}$, an average snow density of about $390 \mathrm{~kg} \mathrm{~m}^{-3}$ with little fluctuation, and an annual accumulation rate of $<5 \mathrm{~g} \mathrm{~cm}^{-2} \mathrm{a}^{-1}$; coarse to very coarse snow grains were found. The combination of low accumulation rate and strong temperature gradient induces snow-grain growth to form coarse grains that are mostly depth hoar, which can become $8 \mathrm{~mm}$ across. Also the sublimation effect causes summer layers to disappear (Giovinetto, 1963).

Figure 6 displays the measured snow grain-sizes and number of layers from the surface down to $2 \mathrm{~m}$. To enable comparison of the snow-pit characteristics, a mean snow grain-size $\Phi_{\mathrm{m}}$ was calculated. Snow grains were classified according to their diameter, $\Phi$, into four classes: fine $(\Phi<0.5 \mathrm{~mm})$, medium $(0.5 \leq \Phi<1 \mathrm{~mm})$, coarse $(1 \leq \Phi$ $<2 \mathrm{~mm})$ and very coarse grains $(\Phi \geq 2 \mathrm{~mm})$. Then a representative grain-size $\Phi_{l}$ of each snow type was defined: from fine to very coarse: $0.2,0.75,1.5$ and $3 \mathrm{~mm}$. The mean grain-size was calculated as follows:

$$
\Phi_{\mathrm{m}}=\sum_{i=1}^{4} \Phi_{i} d_{i} / \sum_{i=1}^{4} d_{i},
$$

where $i$ is the snow type, and $d_{i}$ is the total thickness of layers of type $i$. $\Phi_{\mathrm{m}}$ was calculated over the first $30 \mathrm{~cm}, 1 \mathrm{~m}$ and $2 \mathrm{~m}$. For more details on the snow-pit analysis method, see Surdyk and Fily $(1993,1995)$. Snow-pit locations 101-106 are shown in Figures 4 and 5; they deviate from the A-B-C route, but I assume that inside of one contour line the snow condition remains the same over the entire region. Some snow pits are near the $175 \mathrm{~K}$ contour line of the main patch. Snow pits 101 and 102 are clearly in a high- $\mathrm{TB}_{37}$ area; pits 104 and 105 are near 180 and $175 \mathrm{~K}$, respectively, which are low 
but not minimum TB $_{37}$ values. Pit 103 is near the $185 \mathrm{~K}$ contour line, which is between the high and low values. In Figure 6, the mean grain-sizes in snow pits 101 and 102 are smaller over 1 and $2 \mathrm{~m}$ than those at pits 103, 104 and 105. The largest snow grains are at pit 105 which has a low $\mathrm{TB}_{37}$ value. This agrees with the interpretation of the satellite data: larger snow grains where $\mathrm{TB}_{37}$ is low, and smaller grains where $\mathrm{TB}_{37}$ is high. Moreover, in the first $30 \mathrm{~cm}$ at station 105 the snow grains are much larger than anywhere else. The large grains found on the surface probably are even larger at depth, resulting in very large snow grains below $2 \mathrm{~m}$. Also significant is the number of snow and crust layers. The number of snow layers is about 50 at pits 101-103, drops to 40 at pit 104, then to 30 at pit 105. This also is in good agreement with the interpretation of the satellite measurements. In the low- $\mathrm{TB}_{37}$ area, the $\mathrm{PR}_{10.7}$ indicated a low stratification, thus suggesting a higher net accumulation; the small number of snow layers in the top $2 \mathrm{~m}$ means that snow layers are thicker at pit 105. Furthermore, no crust layers were observed in pits 104 and 105. This would suggest weakening of the wind activity or absence of wind.

\section{INTERPRETATION}

The undulations of the ice-sheet surface created originally by the ice flow over the bedrock topography create an inhomogeneous depositional environment. In a katabatic zone, the net accumulation at a point depends on the precipitation at that point but also on the amount of drift snow redeposited there. The amount of drift snow deposited or eroded by wind is controlled by the surface roughness and its effect on wind activity (Goodwin, 1988; Takahashi and others, 1994). The wind speed is controlled by the regional maximum of the surface slope.

A plausible explanation for the change of the brightness temperature over the area is as follows. The wind velocity decreases progressively as the flat area is approached. The sloping area downstream remains in the wind-shadow for tens of $\mathrm{km}$ until the wind velocity strengthens again with the descending slope. The absence of crust layers and absence of snow-megadune fields in the low- $\mathrm{TB}_{37}$ region confirms that, in the flat area and about $50 \mathrm{~km}$ further away, the wind activity decreases. Newly deposited snow is not blown away, building up thicker layers than up- and downslope. Because the whole region undergoes large temperature gradients and high sublimation effects, very coarse snow grains, mainly surface and depth hoar, grow up near the surface without being broken by the wind, and thus grow even larger in the snow cover than in windier places.

The brightness temperature at 37 and $18 \mathrm{GHz}$ is sensitive to the snow grain-size detected by this local change in snow characteristics. The decrease of $\mathrm{TB}_{6.6}$ and $\mathrm{TB}_{10.7}$ can be attributed, not to the increasing snow grain-size, but rather to the absence of wind crusts and weaker snow layering. However, it is not yet clear why the $\mathrm{PR}_{10.7}$ and $\mathrm{PR}_{6.6}$ 's minimum value is $70 \mathrm{~km}$ shifted compared to the $\mathrm{TB}_{37}$ minimum.

\section{GONGLUSIONS}

In the present study, variations in the snow brightness temperature showed that snow characteristics depend on the local conditions of surface slope, wind action and bedrock topography. This area had particularly large gradients in brightness temperature. It has been shown that these resulted from intense snow metamorphism. However, similar cases of intense snow metamorphism in the snow cover resulting from a wind-shadow have been observed in other regions of Antarctica, including areas that do not have low accumulation rate. However, present satellite-borne sensors will detect only areas of scale as large as the one studied here. The present coarse resolution of passive-microwave data, $25 \mathrm{~km}$ at $37 \mathrm{GHz}$ down to $100 \mathrm{~km}$ at $10.7 \mathrm{GHz}$, might not detect smallscale changes, but the physical link between slope and coarse grains like depth hoar should also apply to smaller scale. The coming Advanced Microwave Scanning Radiometer to be launched on board the Advanced Earth Observing Satellite II will surely be an interesting input; the resolution will then be $60 \mathrm{~km}$ at $6.9 \mathrm{GHz}$, about $30 \mathrm{~km}$ at $10.6 \mathrm{GHz}$ and about $10 \mathrm{~km}$ at $36.5 \mathrm{GHz}$.

The brightness temperature varied where the surface slope changed, because of emissivity variations. Therefore, surface emissivity might be used to map surface slope changes in regions where other surface elevation estimates are not reliable. For example, patch a in Figure 5 has emissivity variations similar to those of patch $\underline{c}$; this indicates that the surface slope changes in patch $\underline{\text { a }}$. The surface slope derived from the DEM did not show such a change, but this may be incorrect due to larger DEM errors.

The extensive presence of large depth hoar means that sublimation and condensation processes form most of the ice mass in the ice sheet after deposition. Although microwave signals are only from shallow phenomena at depth scales from $10^{-2}$ to $10^{2} \mathrm{~m}$, another possible application of this work is to use microwave emissions to detect the extent of regions where depth hoar is an initial stage of ice crystals inside of the ice sheet.

\section{ACKNOWLEDGEMENTS}

The passive-microwave data used for this study were provided by the U.S. National Snow and Ice Data Center. The DEM and bedrock topography model BEDMAP used for this analysis were downloaded from the British Antarctic Survey Internet site for the BEDMAP database (http:// www.nerc-bas.ac.uk/public/aedc/bedmap/) (Liu and others, 1999; Lythe and others, 2001). The RADARSAT-1 Antarctic Mosaic is a product of the NASA Pathfinder Project "RADARSAT-1 Antarctic Mapping Program (RAMP)". Canadian partners included the Canadian Space Agency, the Canadian Centre for Remote Sensing and RADARSAT International. U.S. partners included The Ohio State University, NASA's Alaska SAR Facility, NASA's Jet Propulsion Laboratory and Vexcel Corporation. The author thanks R. A. Bindschadler for the critical review and helpful comments.

\section{REFERENGES}

Abdalati, W. and K. Steffen. 1998. Accumulation and hoar effects on microwave emission on the Greenland ice-sheet dry-snow zones. F. Glaciol., 44(148), 523-531

Brisset, L. and F. Rémy. 1996. Antarctic topography and kilometre-scale roughness derived from ERS-1 altimetry. Ann. Glaciol., 23, 374-381.

Budd, W. F. 1970. Ice flow over bedrock perturbations. F. Glaciol., 9(55), 29-48. Endo, Y. and K. Fujiwara. 1973. Characteristics of the snow cover in East Antarctica along the route of the JARE South Pole traverse and factors controlling such characteristics. JARE Sci. Rep., Ser. C 7, 1-27.

Fahnestock, M. A., T. A. Scambos, C. A. Shuman, R. J. Arthern, D. P. Wine- 
brenner and R. Kwok. 2000. Snow megadune fields on the East Antarctic Plateau: extreme atmosphere-ice interaction. Geophys. Res. Lett., 27(22), 3719-3722

Fily, M. and J.-P. Benoist. 1991. Large-scale statistical study of Scanning Multichannel Microwave Radiometer (SMMR) data over Antarctica. 7. Glaciol., 37(125), 129-139.

Giovinetto, M. B. 1963. Glaciological studies on the McMurdo-South Pole traverse, 1960-1961. Ohio State Univ. Inst. Polar Stud. Rep. 7.

Goodwin, I. D. 1988. Ice sheet topography and surface characteristics in eastern Wilkes Land, East Antarctica. ANARE Res. Notes 64

Hall, D. K. 1987. Influence of depth hoar on microwave emission from snow in northern Alaska. Cold Reg. Sci. Technol., 13(3), 225-231.

Houghton, J.T., G. J. Jenkins and J. J. Ephraums. 1990. Climate change: the IPCC scientific assessment. Cambridge, etc., Cambridge University Press.

Liu, H., K. C. Jezek and B. Li. 1999. Development of an Antarctic digital elevation model by integrating cartographic and remotely sensed data: a geographic information system based approach. F. Geophys. Res., 104(B10), 23,199-23,213.

Lythe, M. B., D. G. Vaughan and BEDMAP Consortium. 2001. BEDMAP: a new ice thickness and subglacial topographic model of Antarctica. 7. Geophys. Res., 106(B6), 11,335-11,351.

Mätzler, C. 1987. Applications of the interaction of microwaves with the natural snow cover. Remote Sensing Rev., 2, 259-387.

Parish, T. R. and D. H. Bromwich. 1987. The surface windfield over the Antarctic ice sheets. Nature, $\mathbf{3 2 8}(6125), 51-54$

Rott, H., K. Sturm and H. Miller. 1993. Active and passive microwave signatures of Antarctic firn by means of field measurements and satellite data. Ann. Glaciol., 17, 337-343.

Surdyk, S. and M. Fily. 1993. Comparison of the passive microwave spectral signature of the Antarctic ice sheet with ground traverse data. Ann. Glaciol., 17, 161-166.

Surdyk, S. and M. Fily. 1995. Results of a stratified snow emissivity model based on the wave approach: application to the Antarctic ice sheet. $\mathcal{F}$. Geophys. Res., 100(C5), 8837-8848.

Takahashi, S., Y. Ageta, Y. Fujii and O. Watanabe. 1994. Surface mass balance in east Dronning Maud Land, Antarctica, observed byJapanese Antarctic Research Expeditions. Ann. Glaciol., 20, 242-248. 